\title{
Development and Evaluation of Colon Targeted Drug Delivery System by Using Natural Polysaccharides/Polymers
}

\author{
G.R. Godge ${ }^{1}$ and S.N. Hiremath ${ }^{2}$ \\ ${ }^{1}$ P.D.V.V.P.F'S College of Pharmacy, Vilad Ghat, Ahmednagar-414111, India \\ ${ }^{2}$ PRES'S College of Pharmacy, a/p Chincholi, Sinnar, Nashik-422101, India
}

Received: September 05, 2013; Accepted: November 20, 2013; Published (web): June 29, 2014

\begin{abstract}
Colon is being extensively investigated as a drug delivery site. This study contains comparison of the usual enteric coating polymers viz. xanthan gum, guar gum, chitosan and ethyl cellulose, as carriers for colon specific drug delivery. Lactose based metoprolol succinate tablets were prepared. These were coated with one of the coating polymers to a varying coat thickness. Tablets were prepared using polysaccharides or synthetic polymer as binders. These included xanthan gum, guar gum, chitosan and ethyl cellulose. Metoprolol Succinate was used as a model drug. The prepared tablets were enteric coated with kollicoat MAE 100 DP to give protection in the stomach. The coated tablets were tested in-vitro for their suitability as colon specific drug delivery systems. The drug release studies were carried out in simulated stomach environment $(\mathrm{pH} 1.2)$ for $2 \mathrm{~h}$ followed by small intestinal environment at $\mathrm{pH}$ 6.8. The dissolution data obtained from tablets demonstrates that the dissolution rate of the tablet is dependent upon the type and concentration of polysaccharide/polymer used as binder. The results demonstrate that enteric coated tablets containing $3 \%$ chitosan as a binder, showed only $12.5 \%$ drug release in the first $5 \mathrm{~h}$, which is the usual upper gastrointestinal transit time, whereas, tablets prepared using guar gum as binder, were unable to protect drug release under similar conditions. Preparations with xanthan gum as a binder formed time-dependent release formulations. When used in a concentration of $5.92 \%$ in the tablets, $28 \%$ drug release was observed in the usual upper gastrointestinal tract conditions. It was also found that enteric coated preparation formulated with $8.88 \%$ of kollicoat MAE $100 \mathrm{DP}$ as binder could be used to carry water insoluble drug molecules. The above study shows that chitosan could be successfully used as a binder, for colon targeting of water insoluble drugs in preference to guar gum when used in the same concentration. Additionally, formulations developed with chitosan and kollicoat MAE 100 DP would be highly site specific since drug release would be at a retarded rate till microbial degradation or polymer solubilization takes place in the colon.
\end{abstract}

Key words: Enteric coating, shellac, colon specific drug delivery, colon targeting, solubilizsation.

\section{INTRODUCTION}

Colonic drug delivery has gained increased importance not just for the delivery of drugs for the treatment of local diseases of colon such as irritable bowel syndrome, inflammatory bowel disease (IBD) including Crohn's disease and ulcerative colitis but also for its potential for the delivery of proteins and therapeutic peptides like insulin. ${ }^{1,2}$ Recently colon has emerged as a potential site which offers distinct advantages on account of a near neutral $\mathrm{pH}$, a much longer transit time, reduced digestive enzymatic activity, much greater response to absorption enhancers, and the presence of large amounts of

Correspondence to: G.R. Godge

Ph: +919028757508, Fax: 0241-2778044

E-mail: grgodge@yahoo.com

Dhaka Univ. J. Pharm. Sci. 13(1): 105-113, 2014 (June) enzymes for polysaccharides (e.g., $\beta$-D-glucosidase, $\beta$-D-galactosidase, amylase, pectinase, xylase, dextranase, etc.) which were secreted by a large number and variety of colonic bacteria., ${ }^{3,4}$ Most of the systems which have been developed for colonspecific drug delivery till date includes coating with pH-sensitive polymers, covalent linkage of a drug with a carrier, time dependent release systems, and enzymatically controlled delivery systems. ${ }^{5}$ Enteric coated systems, though they are the most commonly used for colonic drug delivery systems do not allow reproducible drug release. The disadvantage of this system is that the $\mathrm{pH}$ difference between small intestine and colon is not being very pronounced. Moreover, the limitation of time dependent release system is that it is not able to sense any variation in 
the upper gastro-intestinal tract transit time, any variation in gastric emptying time may lead to drug release in small intestine before arrival to colon. Therefore, the most convenient approach known for site-specific drug delivery to colon is enzymatically controlled delivery systems. No drug release can occur unless the system arrives to the colon. ${ }^{6}$ Many protein and peptide drugs like insulin, cannot be administered through the oral route because of their degradation by the digestive enzymes of the stomach and the small intestine. To improve the specificity of drug release, certain types of neutral polysaccharides (e.g., pectin, xanthin gum chitosan, dextran, guar gum, and inulin) can be used to create the enzymatically controlled delivery systems. To reach the colon and to be able to specifically deliver a peptide or a protein drug, the dosage form must be formulated taking into account the obstacles of upper gastro-intestinal tract and advantages of colonic environment. $^{7,8}$ Polysaccharides can be easily modified chemically and biochemically and are highly stable, safe, nontoxic, hydrophilic and gel forming and in addition biodegradable, which suggests their use in targeted drug delivery systems. They are polymers of monosaccharide's (sugars). They are found in abundance, have wide availability, and are inexpensive and available in a variety of structures with a variety of properties. ${ }^{9}$ Metoprolol succinate is a selective $\beta_{1}$ receptor blocker used in treatment of several diseases of the cardiovascular system, especially hypertension. Metoprolol is used for a number of conditions including: hypertension, angina, acute myocardial infarction, supraventricular tachycardia, ventricular tachycardia, congestive heart failure, and prevention of migraine headaches ${ }^{10}$. It is freely insoluble in water, freely soluble in acetone, soluble in alcohol. Metoprolol undergoes ahydroxylation and O-demethylation as a substrate of the cytochrome liver enzymes CYP2D6 ${ }^{11}$ and a small percentage by CYP3A4. It is selective, moderately lipophilic drug without intrinsic sympathomimetic activity (ISA). Due to its short half-life, therefore must be taken at least twice daily or as a slow-release preparation. The purpose of this study was to formulate a dosage form which was enteric coated to prevent drug release in the stomach and had an additional lag phase in the formulation to retard drug release in the small intestine. Although enteric coated systems with such lag phases have been developed earlier, but being relatively complex systems, their large scale manufacturing requires a lot of technological advancement and skills. ${ }^{12,13}$ So, an attempt was made to formulate a dosage form, which could be formulated easily, using the usual tableting techniques and usual tableting ingredients, with little modification in the method of processing of the ingredients.

\section{MATERIALS AND METHODS}

Metoprolol succinate was a generous gift from Cadila Healthcare Pvt. Limited (Ahmadabad) India. Guar gum, xanthin gum, ethyl cellulose and chitosan (degree of deacetylation $>85 \%$ ), were obtained as gift samples from Rajesh Chemicals, Mumbai, India. Kollicoat MAE 100 DP was obtained as gift sample from BASF Mumbai. All other ingredients used in the preparation and coating of tablets were of analytical grade.

Preparation of matrix tablets. Matrix tablets using metoprolol succinate and natural polysaccharides were prepared with proper selection of excipients.Various excipients used during preparation of matrix tablet are Avicel $\mathrm{pH} 112$, directly compressible lactose, microcrystalline cellulose, magnesium stearate and talc etc. Binder solution of various natural polysaccharides were prepared as per desired concentration as shown in Table no.1. and granules so prepared using active ingredient were dried in oven at $40^{\circ} \mathrm{C}$.

Preparation of granules. All the powdered ingredients were weighed, mixed and granulated with the binder solution/ paste prepared as above. This mixture was thoroughly blended manually and passed through a sieve with a nominal aperture of $1 \mathrm{~mm}$. The granules prepared were dried in a tray drier at a temperature between 30 and $40^{\circ} \mathrm{C}$ for $4 \mathrm{~h}$. The dried granules were screened, mixed with lubricants and stored for tableting. 
Preparation of core tablets. Tablets weighing $200 \mathrm{mg}$ containing $100 \mathrm{mg}$ of metoprolol succinate were individually punched on a rotary punch tableting machine (CAP Works, Ahmedabad, India) using concave die-punch. The tablets had hardness between 5 and $7 \mathrm{~kg} / \mathrm{cm}^{2}$. Various in process quality control tests were performed on the prepared tablets viz., content uniformity, hardness, friability, disintegration, etc.

Coating of core tablet. Each batch of the tablet was coated with a $12.5 \%$ w/v solution of Kollicoat MAE 100 DP, using a pan coating equipment. PEG-
$400(1.25 \% \mathrm{w} / \mathrm{w})$ was used as a plasticizer. The percent weight increase of each batch of tablet after coating varied between $2.9 \pm 0.04 \%$ w/w.

Swelling studies. Uncoated tablets containing xanthan gum and guar gum as binder in varying concentrations were subjected to swelling studies ${ }^{14,15}$ at a temperature of $37^{\circ} \mathrm{C}$ and at a $\mathrm{pH}$ of 6.8 , using the same buffer that was used for dissolution studies. Swelling studies were conducted in triplicate for each binder concentration. Manually radial swelling of tablet width was noted, from time to time (Figs. 1 and 2).

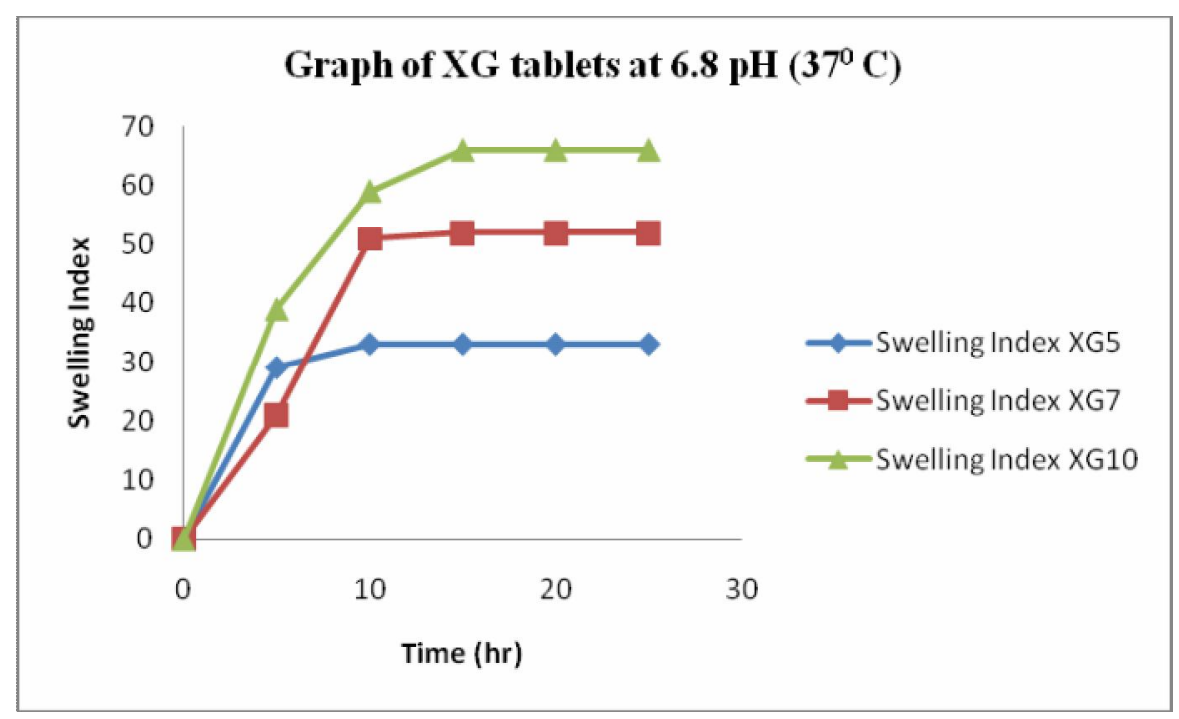

Fig. 1 Swelling index vs. time graph of XG tablets at $6.8 \mathrm{pH}\left(37^{0} \mathrm{C}\right)$

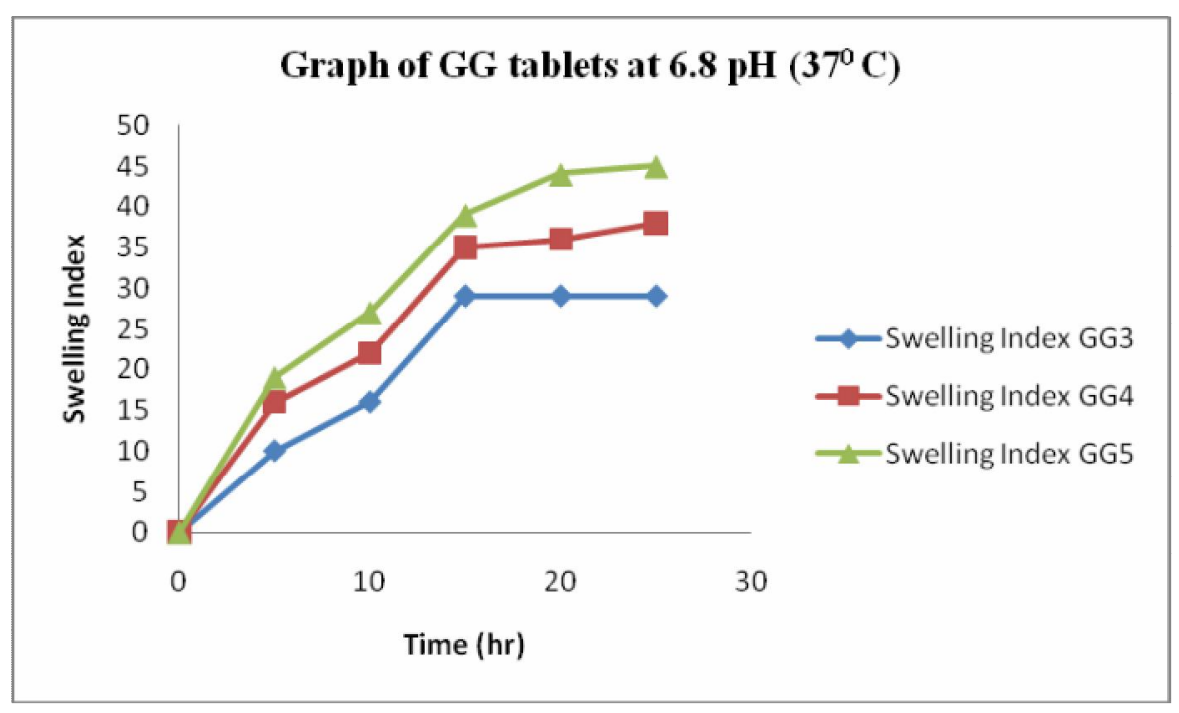

Fig.2 Swelling index vs. time graph of GG tablets at $6.8 \mathrm{pH}\left(37^{0} \mathrm{C}\right)$ 
Drug release studies. The capability of the prepared tablets to retard drug release in the physiological environment of the GIT was assessed by conducting drug release studies in simulated stomach and small intestinal $\mathrm{pH}$, respectively. The changing $\mathrm{pH}$ media, Method 1, USP 23, for delayed release tablets was used. Dissolution test was conducted in USP 1 apparatus at $75 \mathrm{rpm}$ and a temperature of $37^{\circ} \mathrm{C}$. Initial drug release studies were conducted in $750 \mathrm{ml}$ of $0.1 \mathrm{~N} \mathrm{HCl}$ for $2 \mathrm{~h}$. Then, 250 $\mathrm{ml}$ of $0.2 \mathrm{M}$ trisodium phosphate was added to the dissolution media and the $\mathrm{pH}$ adjusted to 6.8. Drug release studies were conducted in triplicate for each polymer/binder concentration. Manually samples were withdrawn after regular intervals of time to evaluate drug release and sink condition were maintained. These were analyzed spectrophotometrically at a wavelength of $230.2 \mathrm{~nm}$.

\section{RESULTS AND DISCUSSION}

For the formulation of a delivery system targeting colon, it is an essential prerequisite that the drug release should be minimal until the dosage form reaches the colon. The normal transit time in the stomach is $2 \mathrm{~h}$ (though this may vary). The transit time in small intestine is relatively constant and is $3 \mathrm{~h}$. So, after gastric emptying, the drug release from the dosage form is to be retarded during transit through the small intestine $(3 \mathrm{~h})$. To overcome the variation in transit time of stomach the tablets prepared were enteric coated. None of the tablets showed drug release during the first $2 \mathrm{~h}$ in $0.1 \mathrm{~N} \mathrm{HCl}$. When the $\mathrm{pH}$ was changed to 6.8 , enteric layer dissolved and further drug release rate was dependent upon the type and concentration of binder used in the tablets.

Xanthan gum as binder. Studies indicated that XG tablets did not show any drug release during the initial $2 \mathrm{~h}$ in the acidic media due to the enteric coating but when the $\mathrm{pH}$ was changed to 6.8 , drug release started, but was found at a retarded rate. The percent drug release from XG5 tablets in the next $3 \mathrm{~h}$ was $24 \%$ and a total of $70 \%$ of the drug was released in $24 \mathrm{~h}$. Upon increasing the concentration of $\mathrm{XG}$ from $2.96 \%$ (XG5) to $4.44 \%$ (XG7), the initial amount of drug release was decreased, showing $22 \%$ release in the next $3 \mathrm{~h}$ but the total amount of drug release in $24 \mathrm{~h}$ was increased to $82 \%$. Further, increase in concentration of xanthan gum to $5.92 \%$ (XG10), though, initially drug release was moderate, but this was followed by a rapid drug release and nearly $100 \%$ drug was released in $18 \mathrm{~h}$.

The rate of drug release which was found to be decreased initially (Fig. 3) upon increasing the concentration of xanthan gum can be explained on the basis that a higher binder concentration led to an increase in hardness of the tablet, while the porosity and capillary pore sizes were reduced ${ }^{16}$. This in-turn reduced the wicking of water into the tablet and consequently the swelling and drug release rates are slowed.

The release of the drug by a matrix system is generally produced by two simultaneous mechanisms: (a) attrition or erosion of the outermost, least consistent gel layer, (b) dissolution of the drug (active principle) in the liquid medium and diffusion through the gel barrier when formed. These tablets showed a considerable swelling at a $\mathrm{pH}$ of 6.8 (Fig. 1) and the drug was dispersed in the swollen matrix formed by the polysaccharide. ${ }^{17-19}$

Past studies carried out on swellable matrices have shown that as the concentration of the swellable polymer is increased in the formulation, the gel thickness increases upon swelling. Due to this it increases the diffusion path length, which in turn decreases the drug release from the tablet $^{14}$. However, in the present study though, upon increasing the polysaccharide concentration, the swelling increased, but after a certain lag phase, the drug release was increased rather than being decreased, which is normally observed from a matrix tablet. This can be explained on the basis that these tablets upon swelling form rather loose gels due to a very low concentration of the polysaccharide. Since the release of drug from these matrices takes place by polysaccharide attrition/erosion, which further depends upon the gel consistency ${ }^{20}$. As gel becomes 
looser, the matrix becomes more susceptible to erosion and hence faster is the drug release. This accounts for the drug release behavior in case of XG tablets. Hence, after an initial lag phase (time taken by the matrix to swell) increase in concentration of binder in XG tablets increases swelling and drug release. Studies indicated that time-controlled release systems for colon targeting can be formulated using $\mathrm{XG}$ as a binder which initially retards drug release due to the lag time required for swelling and after swelling, a rapid drug release was obtained.

Table 1 Quantity of binder in gm for 75 tablets

\begin{tabular}{ccccccc}
\hline $\begin{array}{c}\text { Serial } \\
\text { number }\end{array}$ & $\begin{array}{c}\text { Formulation } \\
\text { code }\end{array}$ & $\begin{array}{c}\text { Xanthin } \\
\text { gum }\end{array}$ & $\begin{array}{c}\text { Guar } \\
\text { gum }\end{array}$ & Chitosan & Ethyl cellulose & Percentage of binder \\
\hline 1. & XG5 & 0.500 & -- & -- & -- & 2.96 \\
2. & XG7 & 0.750 & -- & -- & -- & 4.44 \\
3. & XG10 & 1.00 & -- & -- & -- & 5.92 \\
4. & GG3 & -- & 0.300 & -- & -- & 1.77 \\
5. & GG4 & -- & 0.400 & -- & -- & 2.37 \\
6. & GG5 & -- & 0.500 & -- & -- & 2.96 \\
7. & CH3 & -- & -- & 0.300 & -- & 1.77 \\
8. & CH4 & -- & -- & 0.400 & -- & 2.37 \\
9. & CH5 & -- & -- & 0.500 & -- & 2.96 \\
10. & EC5 & -- & -- & -- & 0.500 & 2.96 \\
11. & EC7 & -- & -- & -- & 0.750 & 4.44 \\
12. & EC10 & -- & -- & -- & 1.00 & 5.92 \\
13. & EC15 & -- & -- & -- & 1.5 & 8.88 \\
\hline
\end{tabular}

Table 2 Cumulative percent drug release from the tablets at varying time intervals $(n=3)$

\begin{tabular}{ccccc}
\hline S1..No. & Tablet code & $\begin{array}{c}\text { Percent drug release } \\
(2 \mathrm{~h})\end{array}$ & $\begin{array}{c}\text { Percent drug release } \\
(5 \mathrm{~h})\end{array}$ & $\begin{array}{c}\text { Percent drug release } \\
(24 \mathrm{~h})\end{array}$ \\
\hline 1. & XG5 & 0 & 24 & 70 \\
2. & XG7 & 0 & 22 & 82 \\
3. & XG10 & 0 & 25 & 100 \\
4. & GG3 & 0 & 68 & 100 \\
5. & GG4 & 0 & 55 & 100 \\
6. & GG5 & 0 & 49 & 100 \\
7. & CH3 & 0 & 16 & 73 \\
8. & CH4 & 0 & 13 & 61 \\
9. & CH5 & 0 & 11 & 49 \\
10. & EC5 & 0 & 83 & 100 \\
11. & EC7 & 0 & 29 & 97 \\
12. & EC10 & 0 & 25 & 84 \\
13. & EC15 & 0 & 19 & 59 \\
\hline
\end{tabular}

Guar gum as a binder. GG tablets shown a rather rapid drug release after second hour of dissolution showing that as the enteric layer dissolved, the gum used as a binder could not effectively retard drug release. In GG3 tablets with a concentration of $1.77 \%$ of gum, drug release could not be retarded. Increasing the concentration of guar gum in the tablet from 1.77 to $2.37 \%$ and then to $2.96 \%$ did retard the drug release profile further but a significant reduction was not observed. The percent drug release versus time graph shows that as much as 68,55 and $49 \%$ drug release was observed in the first 5 h of dissolution of GG3, GG4 and GG5 tablets, respectively (Fig. 4). Complete drug was released from the tablets at around 20th $\mathrm{h}$. Upon increase in concentration of gum in GG tablets increase in swelling index (Fig. 2) was observed even though the drug release was not much affected and no optimum lag time was achieved as required to bypass the drug release in upper parts of GIT. This may be due to the 
concentration of the gum present was not sufficient to retard the drug release, and also lower swelling of guar gum tablets.

Chitosan as a binder. The cumulative percent drug release versus time profile for $\mathrm{CH}$ as binder showed that at a concentration of $1.77 \%$ (in $\mathrm{CH} 3$ tablets), the drug release in the initial $5 \mathrm{~h}$ was $16 \%$. Increasing the concentration of chitosan in the formulation from 1.77 to $2.37 \%$ in $\mathrm{CH} 4$, and then to $2.96 \%$ in $\mathrm{CH} 5$ tablets further retarded drug release from the dosage form. Percent drug release at $5 \mathrm{~h}$ was reduced to $13 \%$ in $\mathrm{CH} 4$ tablets and further to $11 \%$ in CH5 tablets. The total amount of drug released from $\mathrm{CH} 3, \mathrm{CH} 4$, and $\mathrm{CH} 5$ tablets was around $73 \%, 61 \%$ and $49 \%$, respectively in $24 \mathrm{~h}$ (Fig. 5, Table 2).

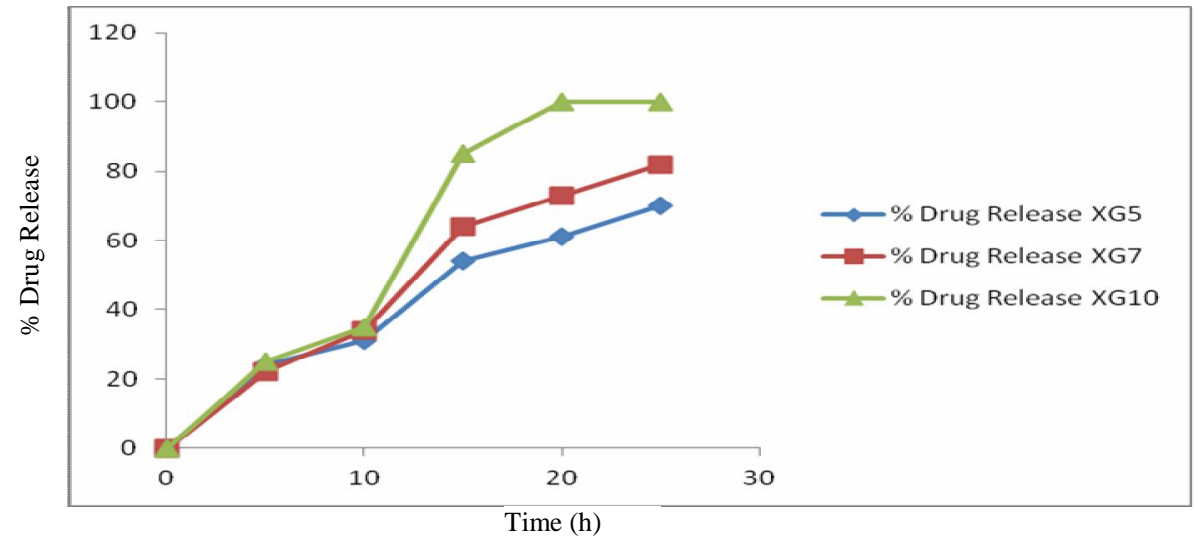

Fig. 3 Percent drug release vs. time graph of XG tablets.

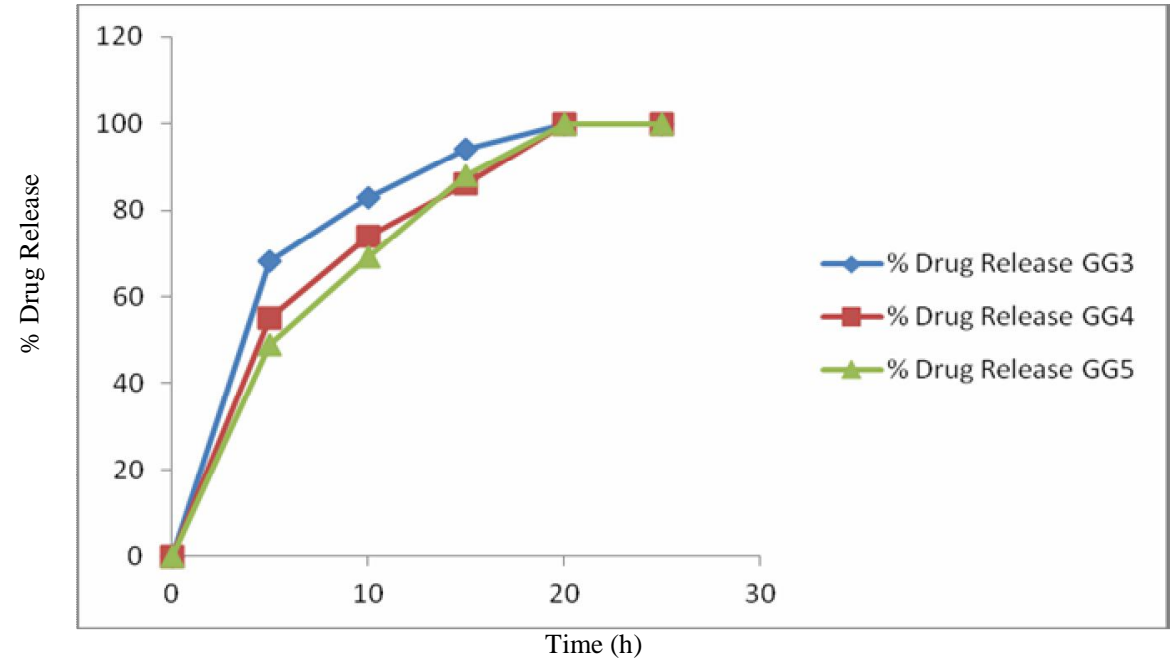

Fig. 4 Percent drug release vs. time graph of GG tablets

This remarkable decrease in release rate after increasing the concentration of chitosan can be explained on the basis that as the concentration of binder in the system is increased, capillary sizes, hardness \& porosity are reduced. Hence, it reduces the wicking of water into the tablet, which decreases the disintegration and in-turn dissolution processes.
These tablets formulated using chitosan did not show any swelling in basic environments, so drug release due to swelling \& polymer erosion was found to be minimized. This explains why the rate of drug release was not as high as in the case of other swellable gums. 
Thus, systems formulated using chitosan as a binder have been found to protect majority of drug release during the usual upper GIT transit time of $5 \mathrm{~h}$. However, there have been a number of reports where chitosan has been found to be digested by the microflora of the colon. Enteric-coated chitosan capsules have been known to be site specific for the colonic delivery of drug molecules, since they release the drug upon bacterial degradation in the colon..$^{21,22}$
Similarly once these $\mathrm{CH}$ tablets reach the colon, chitosan shall be broken down by the microflora of the colon and the total amount of drug shall be released from the dosage form. These tablets can also tolerate variation in upper GIT transit time, since the rate of drug release before arrival into the colon remain retarded. These tablets seem to be highly site specific because drug shall be released only upon specific bacterial degradation of the binding agent i.e. chitosan in the colon.

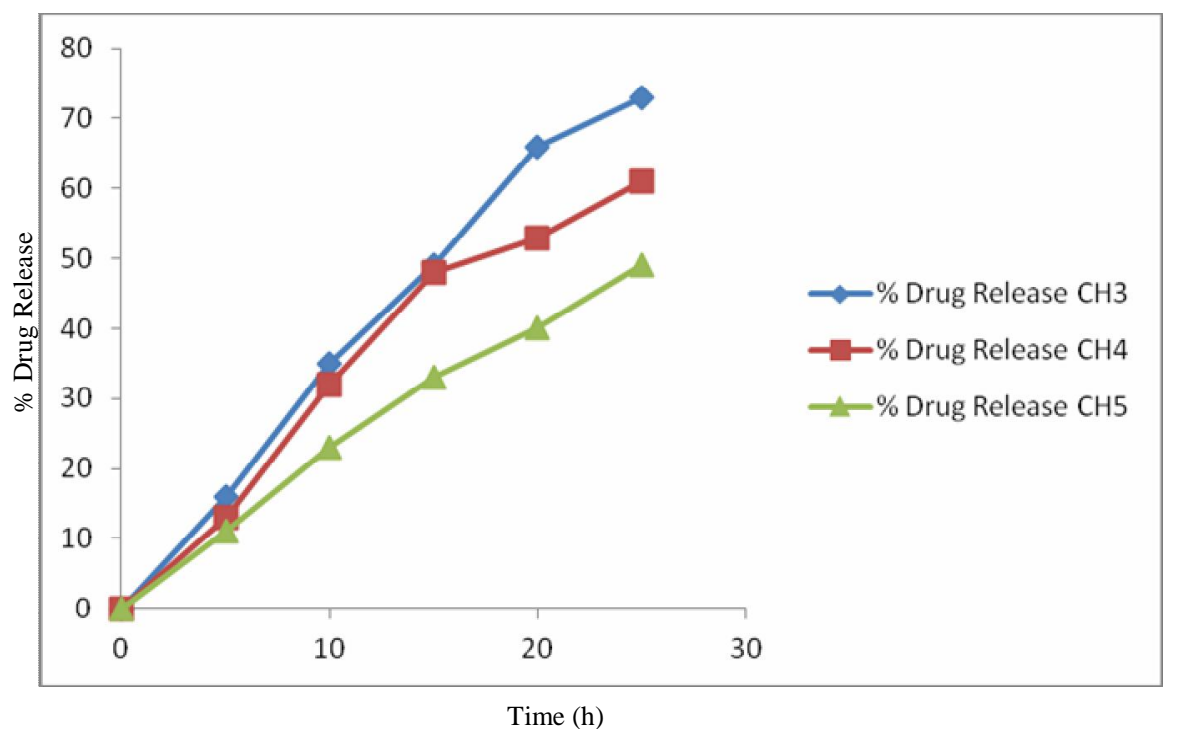

Fig. 5 Percent drug release vs. time graph of $\mathrm{CH}$ tablets.

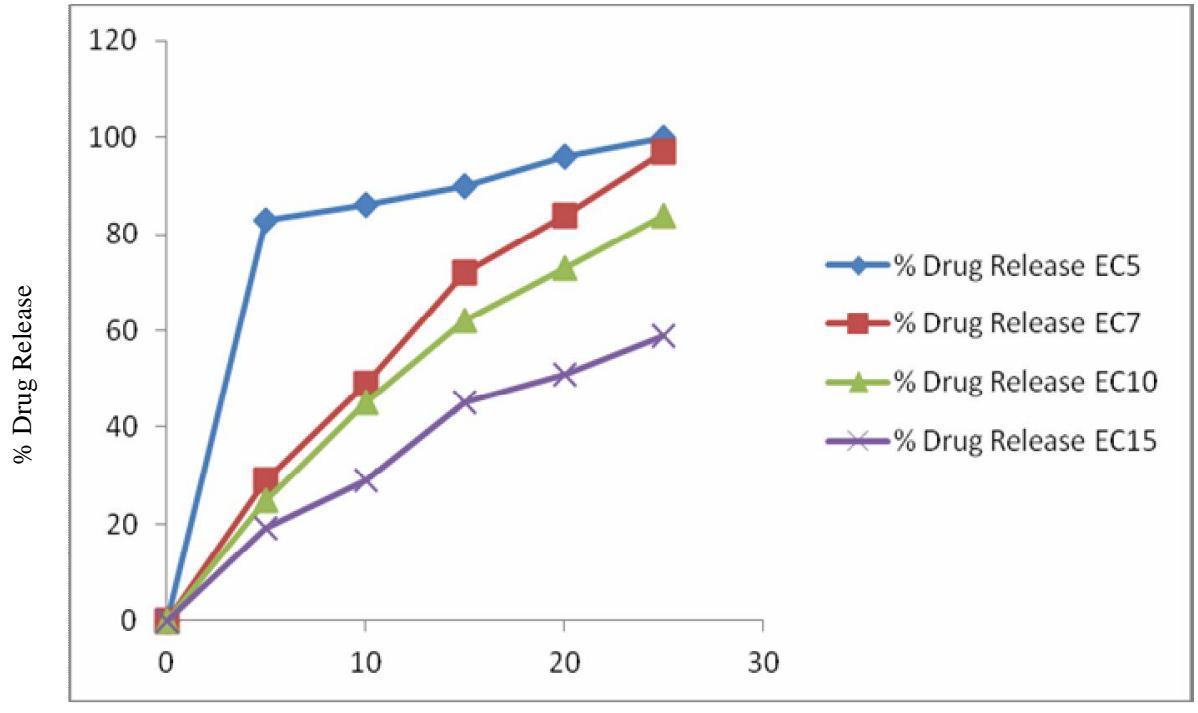

Time (h)

Fig. 6 Percent drug release vs. time graph of EC tablets. 
Ethyl cellulose as binder. Studies indicated that enteric coated system with EC as binders protected drug release for an initial $2 \mathrm{~h}$ in acidic media. In the alkaline environment $(\mathrm{pH}$ 6.8) the enteric layer dissolves, and EC, being soluble only at lower $\mathrm{pH}$ values (lower than 5) finds an unfavourable environment for dissolution and thereby drug release was retarded (Fig. 6). However, a concentration of $2.96 \%$ (i.e. in EC5 tablets) was not able to protect drug release from the tablets and a sharp increase in drug release was observed with-in the next $1 \mathrm{~h}$ and $83 \%$ of drug release was observed in the next $3 \mathrm{~h}$. Upon increasing the concentration of the binder EC in the tablet to $4.44 \%$ (EC7 tablets) the drug release during the first $5 \mathrm{~h}$ of dissolution was retarded showing percent drug release of around $29 \%$ as against $80 \%$ in EC5 tablets. Further increase in concentration of binder to 5.92 and then to $8.88 \%$ in EC 10 and EE 15 tablets, reduced percent drug release in first $5 \mathrm{~h}$ to $25 \%$ and $19 \%$, respectively. The total amount of drug released in $24 \mathrm{~h}$ reduced from 100 to $97 \%$ followed by 84 and then $59 \%$ in EC5, EC7, EC10 and EC15 tablets, respectively (Table 2).

Upon increasing the concentration of binder this reduction in rate of drug release can be explained on the assumption that after drying of granules a film is formed by the binder over the granules. ${ }^{23,24}$ Thickness of the film depends upon the concentration of binder used. More the concentration of binder, thicker the film of ethyl cellulose and was found to be formed around the granules, which retarded the drug release because of being insoluble at a $\mathrm{pH}$ of 6.8. These systems especially EE15 tablets seem to be promising systems for delivery of drugs to the colon in case of chronological disorders. ${ }^{25-28}$

\section{CONCLUSION}

Our studies indicated that the proposed systems seems to be promising for delivery of water soluble drugs to the colon. The use of $5.92 \%$ of xanthan gum as binder could formulate time-controlled release formulations, which could carry a high percentage of drug to the distal part of colon. More over systems formulated using chitosan as binders seems to be highly site specific due to release of majority of drug only upon breakdown by the bacterial microflora of the colon. These formulations could act as colon specific drug delivery systems using as low as $2.96 \%$ of chitosan as binders. Such a low concentration of chitosan has shown high site specificity. An additional advantage of these systems is that they could be formulated easily with reliable practicable method, using the usual tableting and coating techniques. Systems formulated using upto $2.96 \%$ of guar gum could not carry the drug to the colon and found to release their contents in early hours of their administration. Systems formulated with $8.88 \%$ of ethyl cellulose as binders could be used to deliver water soluble drugs site-specifically to the colon in chronological disorders.

\section{ACKNOWLEDGEMENTS}

The authors are thankful to principal of P.D.V.V.P. Foundation' College of Pharmacy, Ahmednagar, Maharashtra for providing necessary facilities without which this work could not possible. Authors are also thankful to Mrs. B.G. Godge for providing necessary technical assistance.

\section{REFERENCES}

1. Chourasia, M., Jain, S.K. 2003. Pharmaceutical approaches to colon targeted drug delivery systems. Eur. J. Pharm. Sci. 6, 32-66.

2. Yang, L., Chu, J.S. and Fix, J.A. 2002. Colon-specific drug delivery: new approaches and in vitro/in vivo evaluation. Int. J. Pharm. 235, 1-15.

3. Sinha, V.R. and Kumria, R. 2001. Polysaccharides in colonspecific drug delivery. Int. J. Pharm. 224, 19-38.

4. Sinha, V. and Kumria, R. 2003. Microbially triggered drug delivery to the colon. Eur. J. Pharm. Sci. 18, 3-18.

5. Leopold, C.S. 1999. Coated dosage forms for colon-specific drug delivery. PSTT. 2, 197-204.

6. Liu, L., Fishman, M., Kost, J. and Hicks, K.B. 2003. Pectinbased systems for colon-specific drug delivery via oral route. Biomaterials 24, 3333-3343.

7. Vandamme, T., Lenourry, A., Charrueau, C. and Chaumeil, J.C. 2002. The use of polysaccharides to target drugs to the colon. Carbohydr. Polym. 48, 219-231. 
8. Saraaija, S. and Hota, A. 2000. Colon-specific drug delivery systems. Int. J. Pharm. Sci. 62, 1-8.

9. Hovgaard, L. and Brondsted, H. 1996. Current applications of polysaccharides in colon targeting. Crit. Rev. Ther. Drug Carrier Syst. 13, 185-223.

10. Cupp, M. 2009. Alternatives for Metoprolol Succinate (pdf). Pharmacist's Letter/Prescriber's Letter 25 (250302). Retrieved 2012-07-06.

11. Swaisland, H., Ranson, M., Smith, R., Leadbetter, J., Laight A., McKillop, D. and Wild, M. 2005. Pharmacokinetic drug interactions of gefitinib with rifampicin, itraconazole and metoprolol. Clinical Pharmacokinetics 44, 1067-1081. $\underline{\text { PMID }} \underline{16176119 .}$

12. MacNeil, M.E. and Stevens, H.N.E., 1990. Patent WO 90/09168.

13. Niwa, K., Takaya, T., Morimoto, T. and Takada, K.1995. Preparation and evaluation of a time-controlled release capsule made of ethyl cellulose for colon delivery of drugs. $J$. Drug Target 3, 83-89.

14. Talukdar, M.M. and Kinget, R. 1995. Swelling and drug release behavior of xanthan gum matrix tablets. Drug Dev. Ind. Pharm. 120, 63-72.

15. Sujja-areevath, J., Munday, D.L., Cox, P.J. and Khan, K.A. 1998. Relationship between swelling, erosion and drug release in hydrophilic natural gum mini-matrix formulations. Eur. J. Pharm. Sci. 6, 207-217.

16. Upadrashta, S.M., Katikaneni, P.R. and Nuessle, N. 1992. Chitosan as a tablet binder. Drug Dev. Ind. Pharm. 18, 17011708.

17. Lapidus, H. and Lordi, N.G. 1968. Drug release from compressed hydrophilic matrices. J. Pharm. Sci. 57, 12921301.

18. Feely, L. and Davis, S. 1988. Influence of polymeric excipients on drug release from hydroxypropyl methyl cellulose matrices. Int. J. Pharm. 44, 131-139.

19. Alderman, D.A. 1984. A review of cellulose ethers in hydrophilic matrices for oral controlled-release dosage form. Int. J. Pharm. Tech. Prod. Mfr. 5, 1-9.
20. Marcos, B.P., Gutierrez, C., Gomez-Amoza, J.L., Martinez. Pacheco, R., Souto, C. and Concheiro, A. 1991. Usefulness of certain varieties of carbomer in the formulation of hydrophilic furosemide matrices. Int. J. Pharm. 67, 113-119.

21. Tozaki, H., Komoike, J., Tada, C., Maruyama, T., Terabe, A., Suzuki, T., Yamamoto, A. and Muranishi, S. 1997. Chitosan capsules for colon specific drug delivery: improvement of insulin absorption from the rat colon. J. Pharm. Sci. 86, 1016-1021.

22. Tozaki, H., Fujita, T., Odoriba, T., Terabe, A., Suzuki, T., Tanaka, C., Okabe, S., Muranishi, S.S. and Yamamoto, A. 1999. Colon specific delivery of R68070, a new thromboxane synthase inhibitor, using chitosan capsules: therapeutic effect against 2, 4, 6,-trinitrobenzene sulphonic acid-induced ulcerative colitis in rats. Life Sci. 64, 1155-1162.

23. Yen, J.K. 1964. The dissolution rate principle in practical tablet formulation. Can. Pharm. J. 97, 493-499.

24. Banakar, U.V. 1992. Factors that influence dissolution testing. In: Pharmaceutical Dissolution Testing. Marcel Dekker, New York, p. 149.

25. Roediger, W., Lawson, M.J., Kwok, V., Grant, A.K. and Pannall, P.R. 1984. Colonic bicarbonate output as a test of disease activity in ulcerative colitis. J. Clin. Pathol. 37, 704707.

26. Sasaki, Y., Hada, R., Nakajima, H., Fukuda, S. and Munakata, A. 1997. Improved localizing method of radiopill in measurement of entire gastrointestinal $\mathrm{pH}$ profiles: colonic luminal $\mathrm{pH}$ in normal subjects and patients with Crohn's disease. Am. J. Gastroenterol. 92, 114-118.

27. Godge, G. and Hiremath, S. 2012. Colonic delivery of film coated meloxicam tablets using natural polysaccharide polymer mixture. Int. Current Pharm. J. 1, 264-271. DOI: http://dx.doi.org/10.3329/icpj.v1i9.11617

28. Hiremath, S. and Godge, G. 2013. Preparation and in vitro evaluation of inclusion complexes of nelfinavir with chemically modified $\beta$-cyclodextrins. Dhaka Univ. J. Pharm. Sci. 11, 107-116. DOI: http://dx.doi.org/10.3329/ dujps. v11i2.14558 